\title{
Comparison Between Bilateral Simultaneous Total Hip Arthroplasty With and Without Drainage; a Retrospective Cohort Study
}

\section{Min-Gwang Kim}

Chonnam National University Hwasun Hospital

\section{Taek-Rim Yoon}

Chonnam National University Hwasun Hospital

Kyung-Soon Park ( $\sim$ chiasma@hanmail.net )

Chonnam National University Hwasun Hospital

\section{Research Article}

Keywords: bilateral simultaneous, total hip arthroplasty, drainage, blood loss, pain, tranexamic acid

Posted Date: June 22nd, 2021

DOl: https://doi.org/10.21203/rs.3.rs-625749/v1

License: () (1) This work is licensed under a Creative Commons Attribution 4.0 International License. Read Full License 


\section{Abstract}

\section{Background}

There are many reports staged bilateral THA without drainage is a better method than with drainage in many ways. However, there is little report regarding bilateral simultaneous THA (BSTHA) without drainage. This study aimed to evaluate the differences in the clinical outcomes and complication rate of BSTHA with drainage and without drainage.

\section{Methods}

Between October 2015 and April 2019, a retrospective cohort study was conducted with modified minimally invasive two-incision method and a consecutive series of 41 BSTHA performed with drainage were compared to 37 BSTHA performed without drainage. It was assessed clinically and radiographically for a mean of $2.1 \pm 0.8$ years (range, 1.0-4.8 years). Postoperative hematologic values (Hgb drop, Hct drop, total blood loss, transfusion rate), pain susceptibility, functional outcome, and complication were compared in the drained group and the non-drained group. All patients preoperatively received intravenous tranexamic acid (TXA) and intraoperatively received intra-articular TXA on each hip. Statistical analyses were performed using the independent $t$ tests, Chi-squared or Fisher's exact tests. A significance level of $\leq 0.05$ was used for all statistical tests.

\section{Results}

Mean postoperative $\mathrm{Hgb}(\mathrm{g} / \mathrm{dL}, \mathrm{p}<0.001)$ \& Hct drop $(\%, \mathrm{p}<0.001)$, mean total blood loss $(\mathrm{ml}, \mathrm{p}<0.001)$ and mean transfusion unit (IU, $p<0.001)$ were significantly lower in the BSTHA without drainage than in the BSTHA with drainage group. But the mean dose of morphine equivalent ( $\mathrm{mg}, \mathrm{p}<0.001)$ was significantly larger in BSTHA without drainage.

\section{Conclusion}

BSTHA without drainage can reduce postoperative blood loss and the requirement for transfusion without increasing other complication. But BSTHA without drainage is more painful method than BSTHA with drainage. Therefore, BSTHA without drainage will be a good option to reduce the burden on the patient by reducing postoperative bleeding if it can control pain well after surgery.

\section{Introduction}

The number of patients undergoing total hip arthroplasty (THA) worldwide is increasing every year due to an increase in the prevalence of osteoarthritis (OA) of the hip joint and osteonecrosis of the femoral head $(\mathrm{ONFH})$, among other causes. Among them, bilateral hip joint disease is so frequent that it can occur in up to $42 \%$ of patients with osteoarthritis, and $25 \%$ of osteoarthritis patients who need THA are estimated to require bilateral arthroplasty [1]. Rheumatoid arthritis, slipped capital femoral epiphysis, developmental 
dysplasia of the hip, and ONFH are also less common causes, but mainly affect both hip joints. These patients are required to undergo a total bilateral hip arthroplasty, sequentially or simultaneously.

Bilateral simultaneous total hip arthroplasty (BSTHA) has many advantages like a shorter hospitalization period, faster rehabilitation, high patient satisfaction, and lower total hospital cost [2-8]. Thus, cases of BSTHA have been recently increasing. However, BSTHA causes more blood loss than staged THA, and patients might require allogenic blood transfusion $[9,10]$. It is well known that allogenic blood transfusion in patients undergoing THA can cause complications, such as infection, delay of rehabilitation, prolonged hospital stay, and increase hospital cost [11].

Multiple efforts have been made for reducing the requirement for allogenic blood transfusion after THA and not using drainage was considered as one of many efforts. There is still controversy over not using drainage after THA; however, not using drainage after THA has been reported to reduce blood loss. There are many reports demonstrating that unilateral THA without drainage can reduce blood loss, and there is no difference in the risk of complications between THA performed with and without drainage [12-14]. However, there is little report regarding BSTHA without drainage [15]. Thus, in this study, we aimed to evaluate the differences in the outcomes of BSTHA with drainage and without drainage and identify any other associated complication.

\section{Material And Methods}

\section{Patients}

We performed a retrospective study on patients who underwent BSTHA for OA of the hip joint or ONFH with a follow-up of at least 1-year at our institution. Between October 2015 and April 2019, 88 patients (176 hips) were treated with modified minimally invasive two-incision method by two surgeons, and the study was approved by the institutional review board.

The inclusion criteria included an American Society of Anesthesiologists (ASA) [16] grade $<4$, body mass index $(\mathrm{BMI})<30$, completed $\geq 1$-year of follow-up, and presence of disease such as OA and ONFH to be treated with simple THA. The exclusion criteria included history of previous hip surgery, follow-up loss during the study period, and severe unilateral or bilateral deformities. Patients with severe deformities of the hip joint and adhesion of the surgical site due to a previous surgery were excluded for easy comparison as this could increase the amount of bleeding during surgery. Finally, a total of 78 patients (156 hips) were eligible for inclusion in the study ( 46 men, 32 women). 41 patients ( 20 men, 21 women) underwent BSTHA with drainage (Group I) and 37 patients (26 men, 11 women) underwent BSTHA without drainage (Group II) (Fig. 1).

\section{Surgical procedure and postoperative management}

All operations were performed using modified minimally invasive two-incision BSTHA in a lateral position, which method uses part of the Watson-Jones approach for anterior incision and part of the Moore 
posterior approach for posterior incision [17]. All patients, except those with thromboembolic tendency, preoperatively received intravenous tranexamic acid (TXA) $500 \mathrm{mg} / 5 \mathrm{ml}$ mixed with $\mathrm{P} / \mathrm{S} 5 \mathrm{ml}$ and intraoperatively received intra-articular TXA $1500 \mathrm{mg} / 15 \mathrm{ml}$ mixed with $\mathrm{P} / \mathrm{S} 35 \mathrm{ml}$ on each hip within safety dose. Femoral implanting using cementless tapered wedge stem was followed by Acetabular implanting using cementless acetabular cup. In group I, before the subcutaneous layer was closed, drainage was inserted the wound was covered with water-proof wound dressing material. After the drainage assembly, patients were drained using positive pressure for 24 hours. After that, negative pressure was maintained until the insertion was removed. The volume of drained blood was recorded every day, and the drain tube was removed if the volume was $<100 \mathrm{~mL}$ [18]. The total blood loss volume was calculated as the intraoperative volume of blood loss plus the blood volume collected in the drainage before the drainage was removed. In Group II, the drainage was not inserted, so the wound was covered with water-proof wound dressing material also used in group I after subcutaneous layer was closed. The total volume of blood loss was calculated as intraoperative blood loss only, because Group II had no drainage.

After the surgery, the patients received one more intravenous TXA $500 \mathrm{mg} / 5 \mathrm{ml}$ mixed with $\mathrm{P} / \mathrm{S} 5 \mathrm{ml}$ and applied intermittent pneumatic compression (IPC) device for the prevention of deep venous thromboembolism. Intravenous patient-controlled analgesia (IV-PCA) was used as a postoperative routine for all patients. Nevertheless, if the patient complained of pain, oral or parenteral opioids like tramadol IV, pethidine IV, or fentanyl transdermal patch were prescribed to control pain during hospitalization.

The same rehabilitation protocol was used for both groups. On the first postoperative day, quadriceps strengthening exercises and ankle dorsiflexion exercise were initiated and ambulation with aid was recommended on the third postoperative day. If the patient's general condition permitted, all patients were scheduled to be discharged within 7 days after surgery.

\section{Clinical outcome measurements}

Hematologic values were checked preoperatively, immediately and on 1, 3, and 5 days after surgery. Estimated blood volume calculated by Nadler formula [19] and the intraoperative volume of blood loss was calculated from the estimated blood volume, initial hematocrit, and immediate hematocrit postoperatively. If the hemoglobin level was $<8.0 \mathrm{~g} / \mathrm{dL}$, patients received red blood cell transfusion and the average transfusion unit (IU) was calculated [20]. We evaluated postoperative pain susceptibility using morphine equivalent conversion formation for quantitative comparison [21]. Functional outcome scoring such as Harris Hip Score (HHS), The Western Ontario and McMaster Universities Osteoarthritis Index (WOMAC) were collected from preoperative visit to final follow up. Lastly occurrence of wound complications (skin necrosis, wound dehiscence, superficial infection), mechanical complications (intraoperative or postoperative periprosthetic fracture) and medical complications (deep vein thrombosis, pulmonary thromboembolism) during hospitalization period and deep infection during follow-up period were assessed.

\section{Statistical analysis}


Statistical analyses were performed using SPSS statistical software system (IBM Corp. Released 2016. IBM SPSS Statistics for Windows, Version 24.0. Armonk, NY: IBM Corp.). Differences in normally distributed variables were analyzed using the independent $t$ tests. Differences in categorical variables between the groups were used to analyze using Chi-squared or Fisher's exact tests. A significance level of $\leq 0.05$ was used for all statistical tests.

Table 1

Demographic details, anesthesia risk and preoperative diagnosis of patients

\begin{tabular}{|c|c|c|c|}
\hline Parameter & With drainage $(\mathrm{N}=41)$ & Without drainage $(\mathrm{N}=37)$ & $P$ value \\
\hline Male/female $e^{\ddagger}$ & $20 / 21(49 \% / 51 \%)$ & $26 / 11(70 \% / 30 \%)$ & 0.054 \\
\hline Age(years) ${ }^{\dagger}$ & $51.8 \pm 11.2$ (range $23-77$ ) & $50.4 \pm 15.1$ (range $25-76$ ) & 0.645 \\
\hline Body mass index ${ }^{\dagger}$ & $24.7 \pm 4.0($ range $18.4-39.8)$ & $24.2 \pm 3.8($ range $18.5-35.3)$ & 0.566 \\
\hline ASA class ${ }^{\ddagger}$ & & & 0.558 \\
\hline 1 & $26(63 \%)$ & $22(59 \%)$ & \\
\hline 2 & $15(37 \%)$ & $14(38 \%)$ & \\
\hline 3 & $0(0 \%)$ & $1(3 \%)$ & \\
\hline Preoperative diagnosis $^{\ddagger}$ & & & 0.410 \\
\hline $\mathrm{ONFH}^{*}$ & 24 (59\%) & $25(67 \%)$ & \\
\hline$O A^{*}$ & $17(41 \%)$ & $12(33 \%)$ & \\
\hline \multicolumn{4}{|c|}{$\begin{array}{l}\text { tIndependent } t \text {-test, } \neq \text { Pearson's chi-square test. Data are presented as median } \pm \text { standard deviation } \\
\text { (range minimum result }- \text { maximum result) and also numbers of patients (percentage). The } p \text {-values } \\
\text { reflect the results of inter-group comparisons, with } p<0.05 \text { indicating significance. }\end{array}$} \\
\hline
\end{tabular}

\section{Results}

The patients' demographic information is summarized in Table 1. There were no differences in patient demographic details such as age, sex, BMI $\left(\mathrm{kg} / \mathrm{m}^{2}\right)$, ASA status between the two groups. The patients were followed clinically and radiographically for a mean of 2.0 years (range, 1.0-3.8 years) in group I and 2.3 years (range, 1.0-4.8 years) in group II.

\section{Hematologic values}

In this study, Fig. 2 showed a decreasing trend of $\mathrm{Hgb}(\mathrm{g} / \mathrm{dL})$ and $\mathrm{Hct}(\%)$ immediately after surgery until 3 days after surgery and then recovered. The non-drainage group had higher $\mathrm{Hgb}$ and $\mathrm{Hct}$ levels than the 
drainage group on the first $(p=0.03$ and $p=0.011)$ and third $(p=0.045$ and $p=0.015)$ postoperative days with significant difference. Whereas there was significant difference between the drainage and nondrainage groups in only Hct levels $(p=0.048)$.

When these changes in the two groups were compared with the average of the preoperative and postoperative measures, there were significant differences between the preoperative and postoperative hematological values (Table 2).

Table 2

Clinical details and perioperative data of the two groups

\begin{tabular}{|c|c|c|c|}
\hline Parameters & With drainage $(\mathrm{N}=41)$ & Without drainage $(\mathrm{N}=37)$ & $P$ value \\
\hline Mean preoperative $\mathrm{Hgb}(\mathrm{g} / \mathrm{dL})^{\dagger}$ & $14 \pm 1.6$ & $13.8 \pm 1.5$ & 0.474 \\
\hline Mean preoperative Hct $(\%)^{\dagger}$ & $41.6 \pm 4.2$ & $41.5 \pm 3.9$ & 0.879 \\
\hline Mean Hgb drop $(\mathrm{g} / \mathrm{dL})^{\dagger}$ & $5.1 \pm 1.3$ & $3.9 \pm 1.0$ & $<0.001$ \\
\hline Mean Hct drop (\%) ${ }^{\dagger}$ & $15.3 \pm 4.2$ & $11.6 \pm 3.0$ & $<0.001$ \\
\hline Mean total blood loss $(\mathrm{ml})^{\dagger}$ & $1684.4 \pm 512.3$ & $732.4 \pm 243.8$ & $<0.001$ \\
\hline Mean transfusion unit $(\mathrm{IU})^{\dagger}$ & $0.7 \pm 1.0$ & $0.1 \pm 0.3$ & $<0.001$ \\
\hline Number of blood recipient (\%) & $18(44 \%)$ & $1(3 \%)$ & $<0.001$ \\
\hline Pain susceptibility $(\mathrm{ME}, \mathrm{mg})^{\dagger}$ & $132.7 \pm 314.1$ & $732.2 \pm 591.5$ & $<0.001$ \\
\hline Mean preop $\mathrm{HHS}^{\dagger}$ & $54.5 \pm 17.7$ & $51.7 \pm 17.5$ & 0.484 \\
\hline Mean preop WOMAC ${ }^{+}$ & $52.4 \pm 16.8$ & $54.4 \pm 18.9$ & 0.624 \\
\hline Mean last f/u HHS ${ }^{\dagger}$ & $90.5 \pm 10.6$ & $93.2 \pm 8.3$ & 0.208 \\
\hline Mean last f/u WOMAC ${ }^{\dagger}$ & $8.2 \pm 6.3$ & $6.0 \pm 6.7$ & 0.151 \\
\hline \multicolumn{4}{|c|}{ 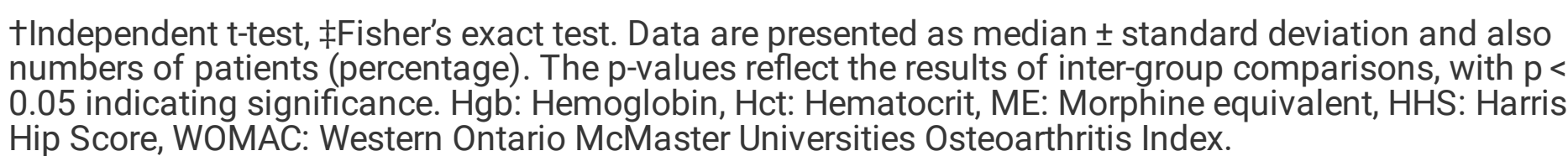 } \\
\hline
\end{tabular}

The mean Hgb drop (Group I: $5.1 \pm 1.3 \mathrm{~g} / \mathrm{dL}$, Group II: $3.9 \pm 1.0 \mathrm{~g} / \mathrm{dL} ; \mathrm{p}<0.001$ ) and the mean Hct drop (Group l: $15.3 \pm 4.2 \%$, Group II: $11.6 \pm 3.0 \% ; \mathrm{p}<0.001$ ) from immediate to postoperative 5 days after BSTHA were different between the two groups. The mean volume of total estimated blood loss was significantly lower in Group II $(732.4 \pm 243.8 \mathrm{ml})$ than in Group I $(1684.4 \pm 512.3 \mathrm{ml}, \mathrm{p}<0.001)$; therefore, the transfusion requirements were significantly lower in Group II (0.1 $\pm 0.3 \mathrm{IU})$ than in Group I $(0.7 \pm 1.0 \mathrm{IU}$, 
$p<0.001)$. As a result, 18 of 41 patients (44\%) in group I received blood transfusions, whereas only 1 of 37 patients $(3 \%, \mathrm{p}<0.001)$ received blood transfusions in group II.

\section{Pain susceptibility}

The mean dose of morphine equivalent $(\mathrm{mg})$ used was significantly larger in Group II (732.2 $\pm 591.5 \mathrm{mg})$ than in Group I $(132.7 \pm 314.1 \mathrm{mg}, \mathrm{p}<0.001)$ (Table 2), which means that the patients in Group II felt more postoperative pain than the patients in Group I.

\section{Functional outcome}

The mean HHS improved in Group I from $54.5( \pm 17.7)$ preoperatively to $90.5( \pm 10.6)$ postoperatively, and in Group II from $51.7( \pm 17.5)$ preoperatively to $93.2( \pm 8.3)$ postoperatively $(p=0.208)$. The mean WOMAC was $52.4( \pm 16.8)$ in Group I and $54.4( \pm 18.9)$ in Group II. This improved to $8.2( \pm 6.3)$ in Group I and 6.0 $( \pm 6.7)$ in Group II $(p=0.151)$.

\section{Complication}

Perioperative complications of both groups are listed in Table 3. In Group I, two hips had an intraoperative fracture, and one hip had a postoperative fracture. Also, six hips had a prophylactic cerclage wire placement for reducing the risk of early periprosthetic fracture. In Group II, two hips had a postoperative fracture, while there were no intraoperative fractures. Also, three hips had a prophylactic cerclage wire placement. Superficial infection occurred in one hip only in Group I and responded to local wound care and antibiotics. Skin necrosis, wound dehiscence, deep infection and medical complications such as DVT, PTE was not detected in any group. 
Table 3

Perioperative complications of both groups, by number and percentage.

\begin{tabular}{|c|c|c|c|}
\hline Parameters & $\begin{array}{l}\text { With drainage } \\
\text { ( } N=41,82 \text { hip) }\end{array}$ & $\begin{array}{l}\text { Without drainage } \\
\text { ( } N=37,74 \text { hip) }\end{array}$ & $P$ value \\
\hline \multicolumn{4}{|l|}{ Wound comlpications } \\
\hline Skin necrosis ${ }^{\dagger}$ & $0(0.0 \%)$ & $0(0.0 \%)$ & 1 \\
\hline Wound dehiscence $^{\dagger}$ & $0(0.0 \%)$ & $0(0.0 \%)$ & 1 \\
\hline Superficial infection ${ }^{\dagger}$ & $1(1.2 \%)$ & $0(0.0 \%)$ & 0.344 \\
\hline \multicolumn{4}{|c|}{ Mechanical complications } \\
\hline \multicolumn{4}{|l|}{ Periprosthetic fracture } \\
\hline - Intraoperative ${ }^{\dagger}$ & $2(2.4 \%)$ & $0(0.0 \%)$ & 0.159 \\
\hline - Postoperative ${ }^{\dagger}$ & $1(1.2 \%)$ & $2(2.7 \%)$ & 0.504 \\
\hline Prophylactic wiring $^{\dagger}$ & $6(7.3 \%)$ & $3(4.0 \%)$ & 0.386 \\
\hline \multicolumn{4}{|l|}{ Medical complications } \\
\hline $\mathrm{DVT}^{\dagger}$ & $0(0.0 \%)$ & $0(0.0 \%)$ & 1 \\
\hline $\mathrm{PTE}^{\dagger}$ & $0(0.0 \%)$ & $0(0.0 \%)$ & 1 \\
\hline Deep infection ${ }^{\dagger}$ & $0(0.0 \%)$ & $0(0.0 \%)$ & 1 \\
\hline
\end{tabular}

\section{Discussion}

Regardless of the use of drainage, the two groups presented similar results in clinical outcomes such as functional score and complications at a mean follow up of 25 months. The most important finding of this study was disusing of drainage reduces loss of bleeding and minimizes the requirement of blood transfusions after BSTHA.

Unlike the current situation where the demand for BSTHA is increasing, there is little report about BSTHA without drainage. So this study was conducted with our expectation of the superiority of BSTHA without drainage. Blood loss was found to be less in the non-drainage group compared to that in the drainage group. In non-drainage group, this may be a consequence of the absence of blood loss into the drain and of none of the reduced effectiveness of topical TXA that was drained immediately with drainage. Many 
studies have described a positive correlation between non drainage and clinical outcomes after THA, which is consistent with the results of this study $[13,14]$.

Other strategies have been attempted to minimize blood loss recently. Among them, TXA is in the spotlight in reducing perioperative blood loss in total joint arthroplasty, recently [22]. Previous articles have demonstrated that a combined administration of TXA in THA is associated with a significantly reduced total blood loss and was safe for patients who received intravenous administration and topical application of TXA [23]. Steven BP et al. proved that it is safe to use in high risk patients with prothrombotic conditions. This study gives additional credence to the recent clinical guide on TXA administration in THA patients [24].

The higher the blood loss, the higher the incidence of blood transfusions. Blood transfusion requirements tended to be higher for patients in the drainage group. Kim et al. reported in a meta-analysis that allogenic blood transfusion is a significant risk factor for increasing the surgical site infection rate after total hip and knee joint arthroplasty [25]. However, in our study, we found no correlation between allogenic blood transfusion and surgical site infection. Also when drainage is not performed, blood may leak through the wound, which disrupts wound healing and may cause a surgical site infection. But in our study, there were no wound problem and significant infection cases. Furthermore, the non-drainage group generally showed higher satisfaction with easier movement during dressing of operation site and ambulation because of no drainage line. (Fig. 3).

Along with the positive aspects of without drainage, there were negative aspects as well. Higher morphine equivalent was derived in the patients without drainage, which means they felt more postoperative pain than the patients who underwent BSTHA with drainage. Rajesh and Prashant et al. proved that the presence of drainage significantly reduces opioid consumption during the first 6 hours after total knee arthroplasty [26]. Li S et al. randomly divided the patients undergoing high tibial osteotomy(HTO) into a drainage group and a no drainage group and the results showed that there was improvement of visual analogue scale (VAS) pain score in the non-drainage group until postoperative 5 days [27]. This is supported the fact that suction drainage can decrease immediate postoperative pain by draining hematoma production that results in increased pressure at the surgical site.

In this study, since TXA was used by same method in both groups, the effect could be excluded, but TXA also contributes to reducing postoperative pain. Tranexamic acid is a synthetic derivative of the amino acid lysine and binds the lysine binding sites on plasminogen, interfering with plasminogen binding to fibrin. By inactivating plasmin, TXA can prevent hyperfibrinolysis. Additionally, the coagulation-fibrinolysis process has been identified at interconnecting with inflammatory cascade [28]. Therefore TXA could play a exert an anti-inflammatory effect by inhibiting plasmin-mediated activation of complement, monocytes, and neutrophils recruitment to the implanted biomaterials, which may consequently minimize postoperative pain [29]. Administration of TXA also helps to reduce postoperative pain by reducing intraarticular hemarthrosis [30,31]. But JW Wurtz et al. suggested an opposing opinion about role of TXA reducing postoperative pain. In this study, patients who received topical TXA reported higher mean 24- 
hour pain scores $(P=0.006)$ and requested opioid sooner $(P=0.033)$ compared to patients who did not receive TXA [32].

Several limitations existed in this study. Firstly, sample size is insufficient for a detailed and comprehensive analysis.

Secondly, this was a retrospective cohort study based on the database of a single institute. Thirdly, the mean follow-up period was not long enough to evaluate the long-term clinical outcomes. Fourthly, patients who undergo BSTHA usually have good physical conditions such as ASA grade 1 and 2; therefore, the result remain unknown in less healthier populations. Fifthly, if the satisfaction of patients and medical workers according to the presence of draining was investigated, it would have been a more meaningful study. Lastly, further studies are needed on the effect of TXA on postoperative pain.

\section{Conclusion}

BSTHA without drainage can reduce postoperative blood loss and the requirement for transfusion without increasing other complication. But BSTHA without drainage is more painful method than BSTHA with drainage. Therefore, BSTHA without drainage will be a good option to reduce the burden on the patient by reducing postoperative bleeding if it can control pain well after surgery.

\section{Abbreviations}

BSTHA: Bilateral simultaneous total hip arthroplasty

TXA: Tranexamic acid

OA: Osteoarthritis

ONFH: Osteonecrosis of the femoral head

ASA grade: American Society of Anesthesiologists grade

BMI: body mass index

IPC: intermittent pneumatic compression

IV-PCA: Intravenous patient-controlled analgesia

HHS: Harris Hip Score

WOMAC: The Western Ontario and McMaster Universities Osteoarthritis Index

DVT: Deep venous thrombosis

PTE: Pulmonary thromboembolism 
HTO: high tibial osteotomy

VAS: Visual Analog Scale

\section{Declarations}

\section{Ethics approval and consent to participate:}

The study was conducted with the approval of the institutional review board (IRB) of Chonnam National University Hwasun Hospital. In this study, all methods were performed in accordance with the relevant guidelines and regulations. All participants signed written informed consent to participate in the study. All participants were above 16 years of age. All rights of the patients were protected against any kind of disadvantage and individual matters.

No: CNUHH 2020-183

\section{Consent for publication:}

Not applicable.

\section{Availability of data and materials:}

The datasets used and/or analysed during the current study available from the corresponding author on reasonable request.

\section{Competing interests:}

The authors declare that they have no competing interests.

\section{Funding:}

No funding for this study.

\section{Authors' contributions:}

MG KIM: Collection and analysis of data and writing manuscript.

TR YOON: Make concepts and design of study

KS PARK: Make concepts and design of study. Review and correction of draft manuscript

${ }^{\star \star}$ All authors have read and approved the final manuscript

${ }^{\star \star}$ All authors have agreed it for submission to publish in this journal.

**All authors have agreed to authorship and order of authorship for this manuscript. 
${ }^{\star *}$ All authors have agreed that any changes of authors or order of authors can't be changed if this manuscript is accepted.

\section{Acknowledgements:}

The authors thank all clinical researchers involved in the research we included in this article. This study was not supported by any company or grant.

\section{References}

1. Macaulay W, Salvati EA, Sculco TP, Pellicci PM: Single-stage bilateral total hip arthroplasty. JAAOSJournal of the American Academy of Orthopaedic Surgeons 2002, 10(3):217-221.https://doi: 10.5435/00124635-200205000-00008.

2. Hou J-F, Hu C, Zhang Y, Tian L-Q, Liu Y-Z, Zhang C, Li J: Cost analysis of staged versus simultaneous bilateral total knee and hip arthroplasty using a propensity score matching. BMJ open 2021, 11(3):e041147. https://doi: 10.1136/bmjopen-2020-041147.

3. Kim Y-H, Kwon O-R, Kim J-S: Is one-stage bilateral sequential total hip replacement as safe as unilateral total hip replacement? The Journal of bone and joint surgery British volume 2009, 91(3):316-320. https:// doi: 10.1302/0301-620X.91B3.21817.

4. Trojani C, d'Ollonne T, Saragaglia D, Vielpeau C, Carles M, Prudhon J-L: One-stage bilateral total hip arthroplasty: functional outcomes and complications in 112 patients. Orthopaedics \& Traumatology: Surgery \& Research 2012, 98(6):S120-S123. https:// doi: 10.1016/j.otsr.2012.06.008.

5. Bhan S, Pankaj A, Malhotra R: One-or two-stage bilateral total hip arthroplasty: a prospective, randomised, controlled study in an Asian population. The Journal of bone and joint surgery British volume 2006, 88(3):298-303. https://doi.org/10.1302/0301-620X.88B3.17048

6. Saito S, Tokuhashi Y, Ishii T, Mori S, Hosaka K, Taniguchi S: One-versus two-stage bilateral total hip arthroplasty. Orthopedics 2010, 33(8). https://doi: 10.3928/01477447-20100625-07.

7. Yoshii H, Oinuma K, Tamaki T, Miura Y, Kaneyama R, Shiratsuchi H: Comparison of patient satisfaction after unilateral or simultaneous bilateral total hip arthroplasty through a direct anterior approach: Evaluation using the Japanese Orthopaedic Association Hip Disease Evaluation Questionnaire. Journal of Orthopaedic Science 2016, 21(3):332-335. https://doi: 10.1016/j.jos.2016.01.008.

8. Seol JH, Park KS, Yoon TR: Postoperative complications and costeffectiveness of simultaneous and staged bilateral total hip arthroplasty using a modified minimally invasive two-incision technique. Hip \& pelvis 2015, 27(2):77. https://doi: 10.5371/hp.2015.27.2.77.

9. Tan Z, Cao G, Wang G, Zhou Z, Pei F: Total hospital cost, length of stay, and complications between simultaneous and staged bilateral total hip arthroplasty: a nationwide retrospective cohort study in China. Medicine 2019, 98(11). https://doi: 10.1097/MD.0000000000014687. 
10. Cao G, Huang Z, Huang Q, Zhang S, Xu B, Pei F: Incidence and risk factors for blood transfusion in simultaneous bilateral total joint arthroplasty: a multicenter retrospective study. The Journal of arthroplasty 2018, 33(7):2087-2091. https://doi: 10.1016/j.arth.2018.02.041.

11. Taneja A, El-Bakoury A, Khong H, Railton P, Sharma R, Johnston KD, Puloski S, Smith C, Powell J: Association between allogeneic blood transfusion and wound infection after total hip or knee arthroplasty: a retrospective case-control study. Journal of bone and joint infection 2019, 4(2):99105. https://doi: 10.7150/jbji.30636.

12. Zhou XD, Li J, Xiong Y, Jiang LF, Li WJ, Wu LD: Do we really need closed-suction drainage in total hip arthroplasty? A meta-analysis. Int Orthop 2013, 37(11):2109-2118. https://doi: 10.1007/s00264-0132053-8.

13. Xu H, Xie J, Lei Y, Huang Q, Huang Z, Pei F: Closed suction drainage following routine primary total joint arthroplasty is associated with a higher transfusion rate and longer postoperative length of stay: a retrospective cohort study. J Orthop Surg Res 2019, 14(1):163. https://doi: 10.1186/s13018019-1211-0.

14. Fichman SG, Mäkinen TJ, Lozano B, Rahman WA, Safir O, Gross AE, Backstein D, Kuzyk PR: Closed suction drainage has no benefits in revision total hip arthroplasty: a randomized controlled trial. International orthopaedics 2016, 40(3):453-457. https://doi: 10.1007/s00264-015-2960-y.

15. Kim Y-H, Cho S-H, Kim R-S: Drainage versus nondrainage in simultaneous bilateral total hip arthroplasties. The Journal of arthroplasty 1998, 13(2):156-161. https://doi: 10.1016/s08835403(98)90093-6.

16. Daabiss M: American Society of Anaesthesiologists physical status classification. Indian journal of anaesthesia 2011, 55(2):111. https://doi: 10.4103/0019-5049.79879.

17. Diwanji SR, Park KS, Yoon TR, Seo HY, Wie JS: Bilateral simultaneous two-incision minimally invasive total hip arthroplasty. Journal of Orthopaedic Science 2009, 14(5):517-524. https://doi: 10.5371/hp.2015.27.2.77.

18. Lee G-W, Park K-S, Kim D-Y, Shin Y-R, Yoon T-R: New strategy of closed suction drainage after primary total hip arthroplasty. Acta orthopaedica et traumatologica turcica 2017, 51(3):223-226. https://doi: 10.1016/j.aott.2017.02.010.

19. Nadler SB, Hidalgo JU, Bloch T: Prediction of blood volume in normal human adults. Surgery 1962, 51(2):224-232.

20. Carson JL, Noveck H, Berlin JA, Gould SA: Mortality and morbidity in patients with very low postoperative $\mathrm{Hb}$ levels who decline blood transfusion. Transfusion 2002, 42(7):812-818. https:// doi: 10.1046/j.1537-2995.2002.00123.x.

21. McPherson ML: Demystifying opioid conversion calculations: a guide for effective dosing: ASHP; 2014.

22. Fillingham YA, Ramkumar DB, Jevsevar DS, Yates AJ, Shores P, Mullen K, Bini SA, Clarke HD, Schemitsch E, Johnson RL et al: The Efficacy of Tranexamic Acid in Total Hip Arthroplasty: A 
Network Meta-analysis. J Arthroplasty 2018, 33(10):3083-3089.e3084. https://doi: 10.1016/j.arth.2018.06.023.

23. Peng Zhang MM, Jifeng Li MM, Xiao Wang MM: Combined versus single application of tranexamic acid in total knee and hip arthroplasty: A meta-analysis of randomized controlled trials. Int $\mathrm{J}$ Surg 2017, 43:171-180. https://doi: 10.1016/j.ijsu.2017.05.065.

24. Porter SB, White LJ, Osagiede O, Robards CB, Spaulding AC: Tranexamic Acid Administration Is Not Associated With an Increase in Complications in High-Risk Patients Undergoing Primary Total Knee or Total Hip Arthroplasty: A Retrospective Case-Control Study of 38,220 Patients. J Arthroplasty 2020, 35(1):45-51.e43. https://doi: 10.1016/j.arth.2019.08.015.

25. Kim JL, Park J-H, Han S-B, Cho IY, Jang K-M: Allogeneic blood transfusion is a significant risk factor for surgical-site infection following total hip and knee arthroplasty: a meta-analysis. The Journal of arthroplasty 2017, 32(1):320-325. https://doi: 10.1016/j.arth.2016.08.026.

26. Maniar RN, Pradhan P, Bhatnagar N, Maniar A, Bidwai R, Bindal P: Role of Suction Drain after Knee Arthroplasty in the Tranexamic Acid Era: A Randomized Controlled Study. Clin Orthop Surg 2019, 11(1):73-81. https://doi: 10.4055/cios.2019.11.1.73.

27. Li S, Yang J, Watson C, Lu Q, Zhang M, Miao Z, Luo D, Liu P: Drainage relieves pain without increasing post-operative blood loss in high tibial osteotomy: a prospective randomized controlled study. Int Orthop 2020, 44(6):1037-1043. https://doi: 10.1007/s00264-020-04530-z.

28. Busuttil SJ, Ploplis V, Castellino F, Tang L, Eaton J, Plow E: A central role for plasminogen in the inflammatory response to biomaterials. Journal of Thrombosis and Haemostasis 2004, 2(10):17981805. https://doi: 10.1111/j.1538-7836.2004.00916.x.

29. Jimenez JJ, Iribarren JL, Lorente L, Rodriguez JM, Hernandez D, Nassar I, Perez R, Brouard M, Milena A, Martinez R: Tranexamic acid attenuates inflammatory response in cardiopulmonary bypass surgery through blockade of fibrinolysis: a case control study followed by a randomized double-blind controlled trial. Critical Care 2007, 11(6):1-10. https://doi: 10.1186/cc6173.

30. Pauzenberger L, Domej M, Heuberer P, Hexel M, Grieb A, Laky B, Blasl J, Anderl W: The effect of intravenous tranexamic acid on blood loss and early post-operative pain in total shoulder arthroplasty. The bone \& joint journal 2017, 99(8):1073-1079. https://doi: 10.1302/0301620X.99B8.BJJ-2016-1205.R1.

31. Ma R, Wu M, Li Y, Wang J, Wang W, Yang P, Wang K: The comparative efficacies of intravenous administration and intra-articular injection of tranexamic acid during anterior cruciate ligament reconstruction for reducing postoperative hemarthrosis: a prospective randomized study. $B M C$ Musculoskeletal Disorders 2021, 22(1):1-7. https://doi: 10.1186/s12891-021-03990-7.

32. Wurtz JW, Wurtz LD, Ziemba-Davis M, Deckard ER, Meneghini RM: Topical tranexamic acid increases early postoperative pain after total hip arthroplasty. The Journal of arthroplasty 2020, 35(6):S219S225. https://doi: 10.1016/j.arth.2020.01.069.

\section{Figures}




\section{8 patients}

(Treated with MIS 2-inc BSTHA during 2015 and 2019)

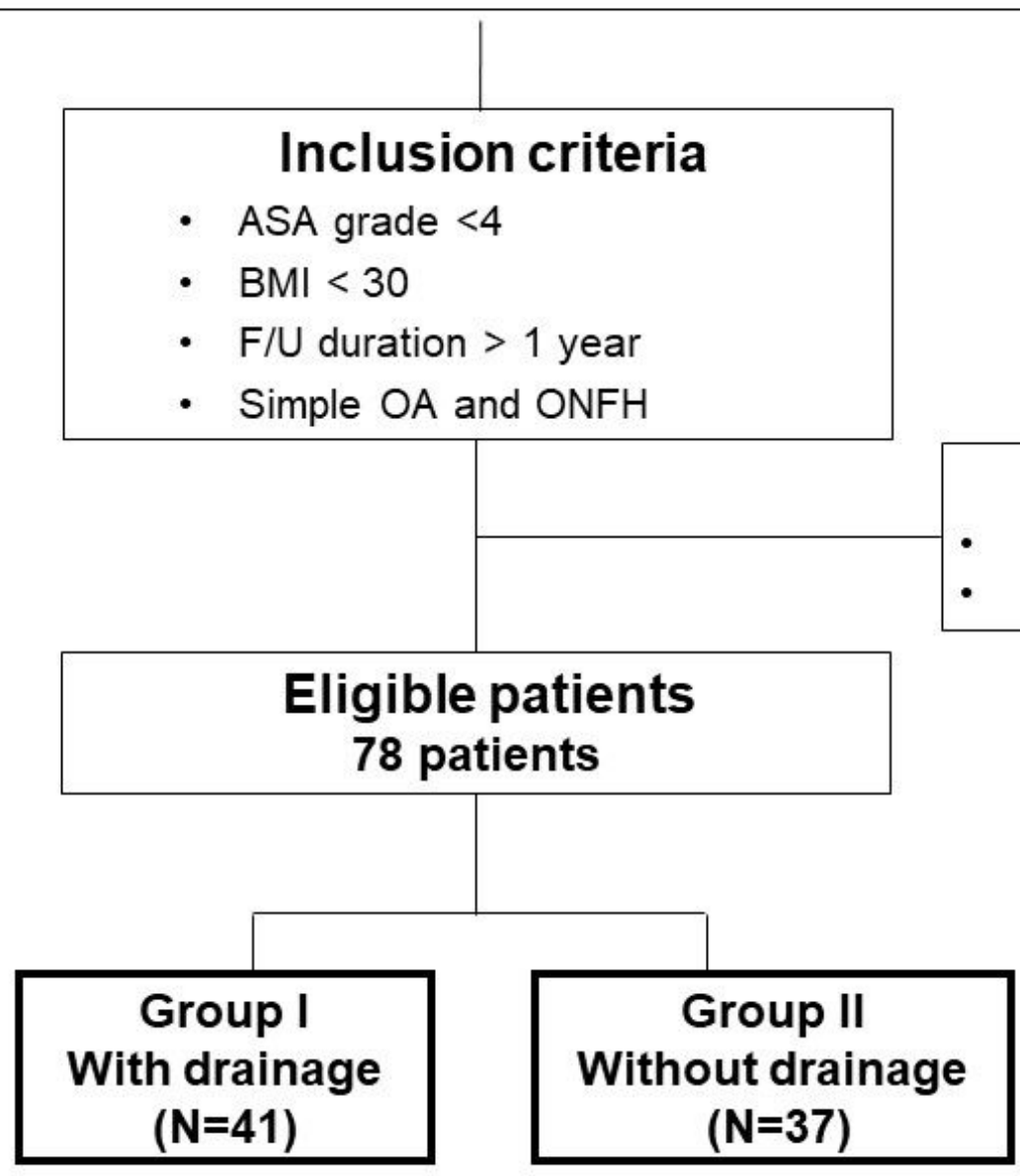

Figure 1

Flow diagram of patient selection

a

15.0

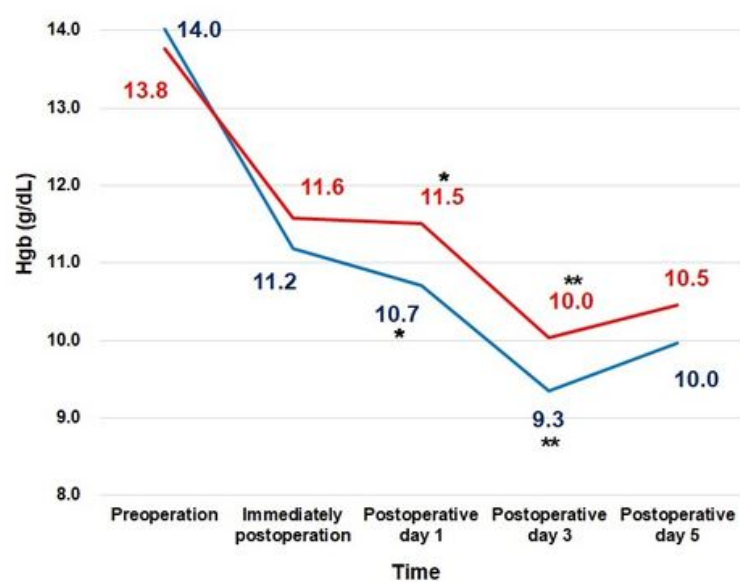

\section{Excluded ( $\mathbf{N}=10)$}

History of previous hip surgery

- Not meeting inclusion criteria

Independent $t$-test for comparison of clinical outcomes between two groups at each time, with $p<0.05$ indicating significance

(a) ${ }^{*} \mathrm{p}=0.03,{ }^{* \star} \mathrm{p}=0.045$ (b) $+\mathrm{p}=0.011,++p=0.015,+++p=0.048$ 
Figure 2

Change of hematologic values between two groups

a
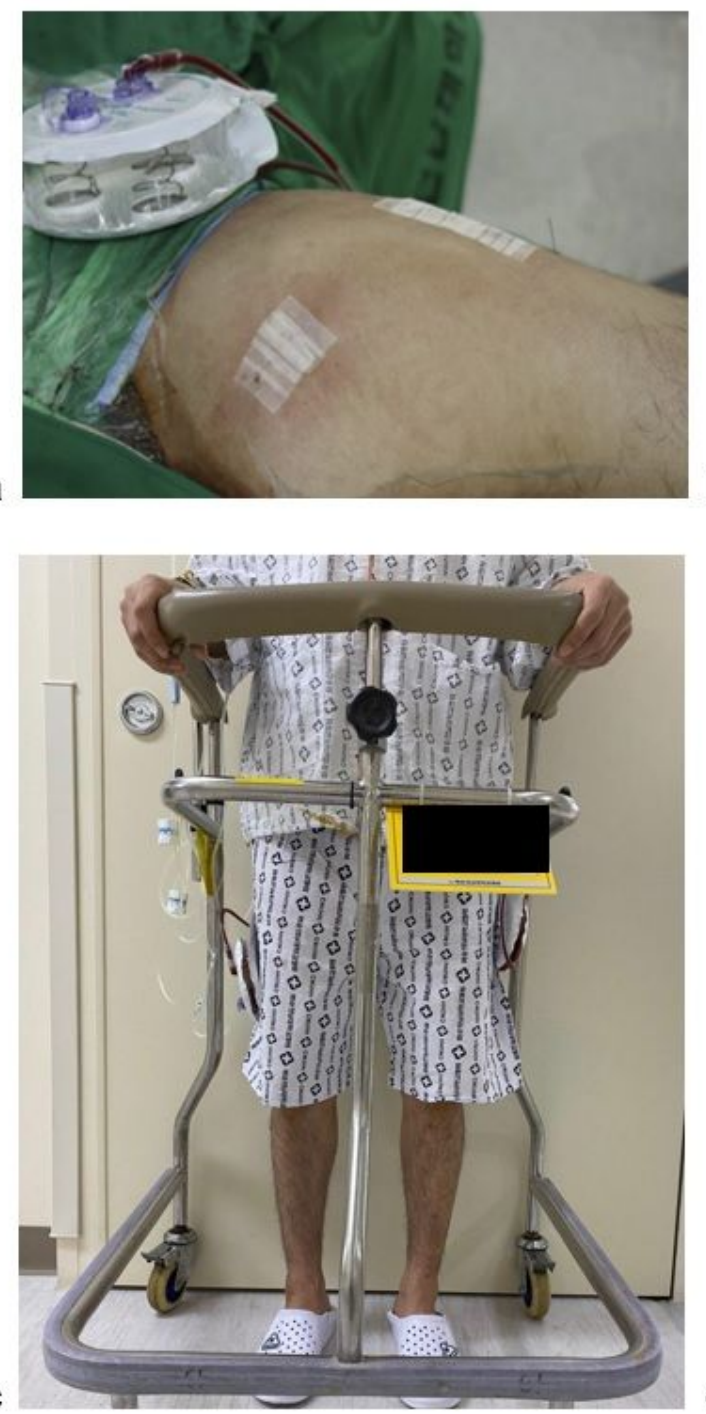

c

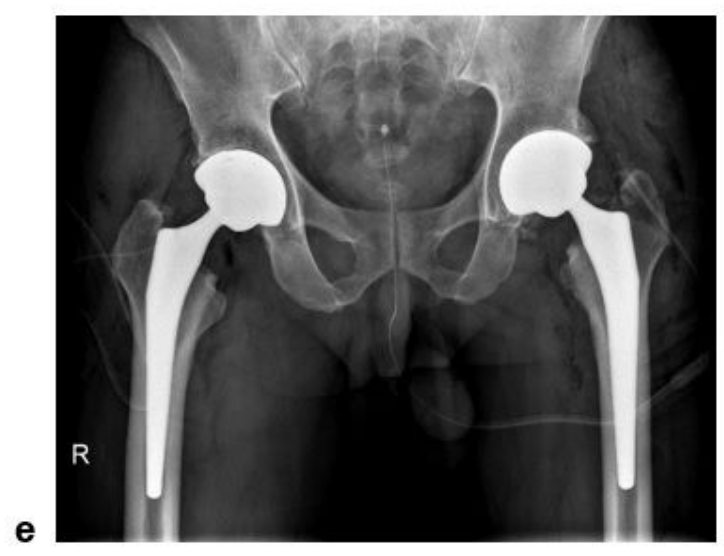

b
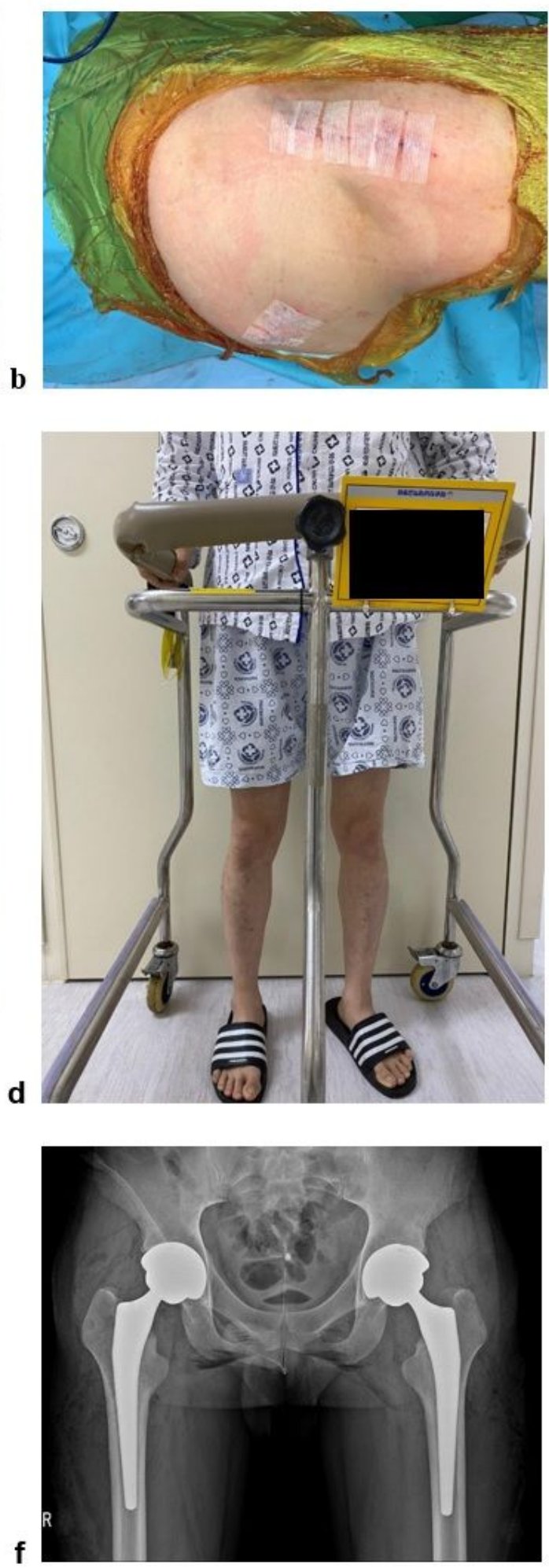

Figure 3

Overall comparison from intraoperative findings to life of hospitalization between two groups $(a, c)$ The patients in group I has drainage line, making it difficult to walk after surgery, and the drainage line may 
pull out due to jamming while walking. (b, d) But the patients in group II has no drainage line, making it more convenient to walk after surgery than the patient with drainage, there was also no risk of disconnection of drainage line. The patient's satisfaction after BSTHA without drainage is higher in our institution. $(e, f)$ These two plain radiographs are pictures of each group immediately after surgery. 